\title{
Facial skin and soft tissue infection caused by Mycobacterium wolinskyi associated with cosmetic procedures
}

\author{
Seung Jin Yoo ${ }^{1 \dagger}$, Keun Hwa Lee ${ }^{2 \dagger}$, Sung-No Jung ${ }^{3 \dagger}$ and Sang Taek Heo ${ }^{4 *}$
}

\begin{abstract}
Background: Mycobacteirum wolinskyi is a member of the Mycobacterium smegmatis group, which is less frequently found in clinical settings than other nontuberculous mycobacterium (NTM) species. However, its clinical significance has recently increased in opportunistic infections. This case is the first report of facial skin and soft tissue infection by M. wolinskyi complicating cosmetic procedures.

Case presentation: A 56-year-old Asian female patient with a history of receiving multiple facial cosmetic procedures over the preceding 2 years was admitted to our institution with swelling, local pain, and erythema on the right cheek. Mycobacteirum fortuitum complex isolated from a pus culture was identified as M. wolinskyi by rpoB sequencing. Metallic foreign bodies and abscess were detected by radiologic imaging. The pus was incised and drained. Treatment comprised clarithromycin (500 mg every 12 h), amikacin (200 mg every 8 h), and ciprofloxacin (400 mg every 6 h).

Conclusion: We report the first case of facial skin and soft tissue infection with $M$. wolinskyi after multiple cosmetic procedures of filler injection and laser lipolysis. Increased occurrence of NTM infection in nosocomial settings suggests the importance of appropriate treatment including culturing and rpoB gene sequencing when patients who have undergone cosmetic procedures display symptoms and signs of soft tissue infection indicative of NTM infection.
\end{abstract}

Keywords: Mycobacterium wolinskyi, Cosmetic, Filler injection, Skin and soft tissue infection

\section{Background}

Among more than 140 species of nontuberculous mycobacteria (NTM), the rapidly growing mycobacteria (RGM), which are widely distributed in soil and water, is a clinically significant pathogen that causes various human diseases [1]. RGM, a type IV mycobacteria under the Runyon classification system, includes the Mycobacterium fortuitum group, Mycobacterium perginum, Mycobacterium chelonae, Mycobacterium abscessus, Mycobacterium immunogenum, and Mycobacterium smegmatis group [2]. Mycobacterium wolinskyi, which belongs to the $M$. smegmatis group, was first identified in 1999 by $16 \mathrm{~S}$ rRNA sequencing [3]. M. wolinskyi is

\footnotetext{
* Correspondence: neosangtaek@naver.com

${ }^{\dagger}$ Equal contributors

${ }^{4}$ Department of Infectious Disease, Jeju National University School of Medicine, Jeju-si, Jeju, South Korea

Full list of author information is available at the end of the article
}

less frequently observed in clinical settings, but it is predominantly associated with skin and soft tissue infections (SSTIs) [4]. Previously reported cases of M. wolinskyi have described its primary association with posttraumatic or postsurgical wounds resulting in cellulitis, osteomyelitis, and localized abscess [5]. Herein, we report the first case of facial SSTI caused by $M$. wolinskyi after multiple cosmetic procedures involving filler injections and laser therapies.

\section{Case presentation}

A 56-year-old Asian female patient was admitted to Jeju National University Hospital with persisting edema that evolved from a small indurated nodule on the right cheek over the course of 3 months (Figure 1). The patient had received multiple AccuSculpt ${ }^{\mathrm{mt}}$ laser procedures $(1444 \mathrm{~mm}$ Nd:YAG) for facial pigmentation removal and lipolysis, and repeated filler injections for cosmetic purposes at a

\section{Ciomed Central}




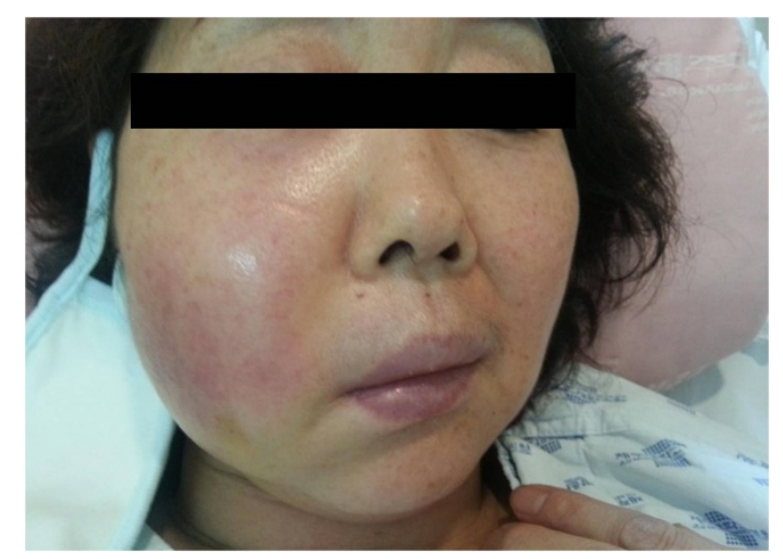

Figure 1 Small indurated nodules with persisting edema on the right cheek.

local clinic since 2011. In August 2012, a subcutaneous indurated nodule approximately 1 to $2 \mathrm{~cm}$ in diameter developed on the right side of the face. She was injected with hyaluronidase and triamcinolone weekly for subcutaneous nodule. However, swelling at the site of erythema progressively developed. Although a local physician prescribed antibiotics with suspected facial cellulitis, the patient's condition did not improve.

The patient did not have any previous surgical and medical history of tuberculosis or diabetes mellitus, but was controlled for hypertension. Physical examination indicated stable vital status. The right facial lesion was generally edematous without a definitely elevated margin in addition to a heating sensation and tenderness at the site of swelling (Figure 1). Initial laboratory findings did not indicate any abnormal results other than elevated C-reactive protein (CRP) $7.13 \mathrm{mg} / \mathrm{dL}$ and erythrocyte sedimentation rate (ESR) of $69 \mathrm{~mm} / \mathrm{h}$. Human-immunodeficiency virus was negative. Chest radiography revealed no apparent active lesions.

Facial computed tomography (CT) indicated multiple metallic foreign bodies, soft tissue infection, and fatty infiltration (Figure 2). Since the patient had a history of cosmetic procedures, and steroid injections and showed no apparent improvement of symptoms in response to $\beta$-lactam antibiotic, pus was collected for acid fast bacilli (AFB) stain, mycobacterium culture, Mycobacterium tuberculosis/NTM polymerase chain reaction (TB/NTM PCR), gram staining, and culture. The results indicated the presence of AFB positive and NTM PCR positive organisms. According to the test results, the antibiotic treatment regimen was changed to clarithromycin $(500 \mathrm{mg}$ every $12 \mathrm{~h}$ ), amikacin (200 mg every $8 \mathrm{~h}$ ), and ciprofloxacin (400 mg every $6 \mathrm{~h}$ ), and NTM culture for pus was performed. Pain at the site of the lesion was improved, but the patient still complained of continuous pus formation. Meanwhile, $M$. fortuitum complex (MFC) was isolated from
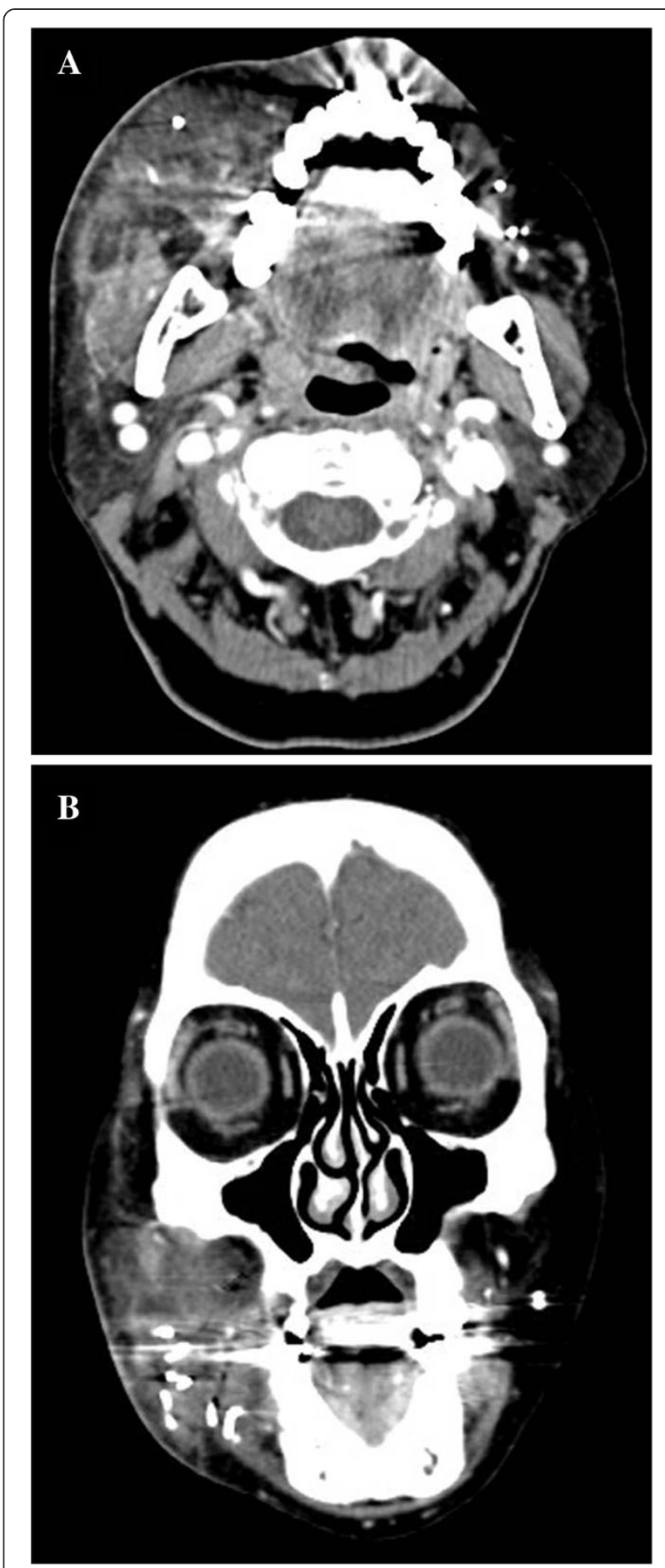

Figure $\mathbf{2}$ Facial computed tomography. A: shows swelling of soft tissue with fatty infiltration on the right side on the axial image $\mathbf{B}$ : scattered longitudinal tube-like shaped lesions of 0.5 to $1 \mathrm{~cm}$ with high density at right mandibular area on the coronal image as well as at the contralateral side.

the NTM pus culture. The results from the antibiotic susceptibility tests are shown in Table 1 . The subsequent $r p o B$ gene sequencing identified $M$. wolinskyi with an accuracy of $99 \%$. 
Since metal foreign body and abscess had been confirmed by radiologic and pathologic images, incision and drainage was performed to eliminate granulation tissue, metallic foreign bodies, and thread remnants (Figures 3 and 4). At the same time, the patient was treated with oral doxycycline (100 mg every $12 \mathrm{~h}$ ) and ciprofloxacin (750 mg every $4 \mathrm{~h}$ ) for 5 months. Subsequently, the facial abscess and erythematous swelling were resolved with minor dermatologic sequelae.

\section{Conclusions}

M. wolinskyi has been reported in only 13 cases since its first categorization within the $M$. smegmatis group in 1999. Contrary to several reported cases of SSTI caused by other NTM species [6-10], previously reported cases of $M$. wonlinskyi-related SSTI mostly described incidences following surgical procedures including hip prosthesis, peritoneal dialysis, transplantation, and heart surgery and posttraumatic events [3,11-13]. Infections have also been observed in immunocompromised patients $[14,15]$ and in some cases of tissue necrosis involving subjacent bone [1]. However, M. wolinskyi infection complicating facial cosmetic procedure has not hitherto been reported, although there are increasing reports of SSTI caused by other RGM species involving cosmetic therapy such as M. fortuitum, M. abscessus, M. jacuzzi and M. concepcionense (Table 2).

In this case, we describe a facial SSTI associated with $M$. wolinskyi, presumably due to invasive cosmetic procedures. The exact route and time of the infection is currently unclear because the patient had received multiple cosmetic procedures involving filler injection, and lipolysis over the course of 2 years. One possible route of infection includes a failure to maintain aseptic procedure during the invasive procedures. Furthermore, the patient also has a history of receiving facial acupuncture procedures in the childhood. Multiple acupuncture needle insertions tend to leave needle remnants at the site of procedures, and would allow $M$. wolinskyi to invade dermis and grow along the existing
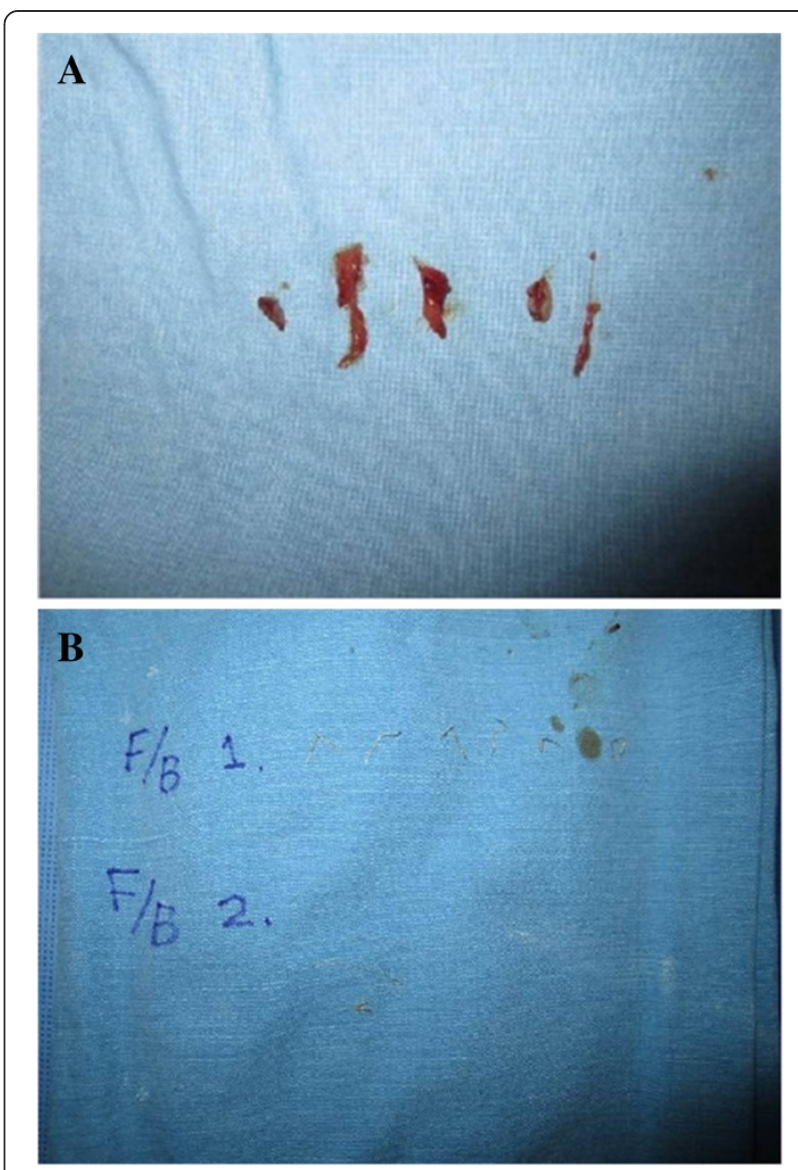

Figure 3 Postoperative images after incision and drainage. A: granulation tissue and $\mathbf{B}$ : Metal foreign body (F/B 1). Remnant thread of previous cosmetic procedure (F/B 2).

metal fragments more rapidly than without any foreign bodies. Facial acupuncture is a widely-performed childhood ritual on Jeju Island for health and longevity.

Culture and laboratory identification of NTM can be a time consuming process because the process relies on growth rate, pigmentation, and several biochemical tests

Table 1 Antibiotics sensitivity test results for Mycobacterium wolinskyi

\begin{tabular}{lccc}
\hline Antibiotic & $\begin{array}{c}\text { Concentration } \\
(\boldsymbol{\mu} \mathbf{g} / \mathbf{m L})\end{array}$ & $\begin{array}{c}\text { Minimum inhibitory concentration } \\
(\boldsymbol{\mu} \mathbf{g} / \mathbf{m L})\end{array}$ \\
\hline Amikacin & $1 \sim 128$ & 8 & $\mathrm{R}$ \\
Cefoxitin & $2 \sim 256$ & 64 & $\mathrm{~S}$ \\
Ciplofloxacin & $0.125 \sim 16$ & $4 \sim 16$ & $\mathrm{~S}$ \\
Clarithromycin & $0.5 \sim 64$ & 2 & $\mathrm{~S}$ \\
Doxycycline & $0.25 \sim 32$ & 16 & $\mathrm{~S}$ \\
Imipenam & $0.5 \sim 64$ & $\mathrm{R}$ & $\mathrm{S}$ \\
Moxifloxacin & $0.125 \sim 16$ & $16 / 304$ & $\mathrm{~S}$ \\
Trimethoprimesulfamethoxazole & $0.25 / 4.75 \sim 32 / 608$ & 8 & $\mathrm{R}$ \\
Linezolid & $2 \sim 64$ & $\mathrm{~S}$ \\
\hline
\end{tabular}

S: susceptible/l: Intermediate susceptibility/R: Resistant/IR: Inducible Resistant. 


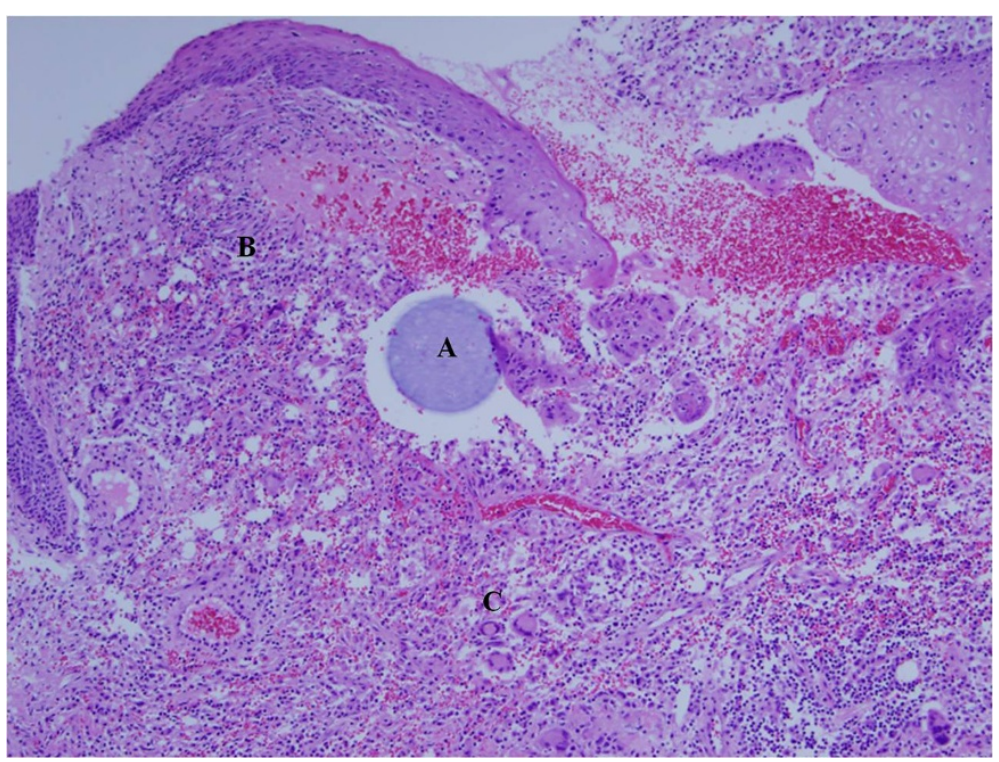

Figure 4 Postoperative histology findings. A: Foreign body in dermis; B: Lymphocytic infiltration surrounding the foreign body; and C: Granulomatous inflammation with multinucleated giant cells (H\&E stain, magnification $\times 100$ ).

[1]. Molecular analysis using $16 \mathrm{~S}$ rRNA and rpoB gene sequencing and TB/NTM PCR screening has made the identification process more rapid and accurate $[4,5]$. In the current case, since PCR and culture results indicated the presence of NTM, rроB gene sequencing analysis was performed using primers MF (5'-CGACCACTTC GGCAACCG-3') and MR (5'-TCGATCGGGCACATC CGG-3') [12]. The isolate was identified as $M$. wolinskyi, whose sequence similarity was $99 \%$ with $M$. wolinskyi ATCC 700010. Since the $r p o B$ gene sequence is more divergent and discriminable for identification of RGM species than $16 \mathrm{~S}$ rRNA sequence [1], we only performed rpoB sequence analysis for prompt identification of NTM species to prevent further delay in diagnosis and treatment in this case.

RGM organisms are generally known to be resistant to standard anti-tuberculosis agents, and treatment for each RGM species differs depending on the susceptibility to antibiotics. In this case, the patient had frequent exposure to medical procedure-related contamination, and the SSTI did not improve with antibiotics and remained for a long duration. Due to its chronic condition and procedure-related infection, not only bacterial but also NTM infections were suspicious. Since Korea is a known tuberculosis endemic area, when infection persists and is resistant to standard antibiotic treatment, tuberculosis infection is more likely than NTM infection. However, failure of standard anti-tuberculosis agents is strongly suggestive of NTM infection. It was also notable that there have been five cases of NTM infection in the Jeju area within a recent year [16].

Treatment regimen with clarithromycin, amikacin, and ciprofloxacin was effective in controlling the infection according to the laboratory results and this patient's condition. The metallic foreign materials embedded at the site of abscess made the progression of NTM SSTI more severe and rapid than expected. When SSTI is associated with foreign materials, the progression of the

Table 2 Summary data of facial skin and soft tissue infection by rapidly growing mycobacterium after cosmetic procedures in the literature

\begin{tabular}{|c|c|c|c|c|c|}
\hline Case & Sex/Age & Type of procedure & Site & Microbiologic finding & Reference \\
\hline 1 & $F / 67$ & Autologous fat graft & Both cheek & M. abscessus & [4] \\
\hline 2 & $\mathrm{~F} / 50$ & Autologous fat graft & Both cheek & M. conceptionense & [4] \\
\hline 3 & $\mathrm{~F} / 50$ & Filler injection & Glabellar area & M. fortuitum & [4] \\
\hline 4 & $M / 66$ & Autologous fat graft & Forehead & M. abscessus & [4] \\
\hline 5 & $\mathrm{~F} / 50$ & Liposuction and lipoinjection & Both cheek & M. conceptionenese & [6] \\
\hline 6 & $\mathrm{~F} / 50$ & Filler injection & Right cheek & M. chelonae & [8] \\
\hline 7 & $\mathrm{~F} / 56$ & Filler injection and accusculpt lipolysis & Right cheek & M.wolinskyi & Current case \\
\hline
\end{tabular}


clinical course of infection could be unusual and faster. In addition, surgical interventions like incision and drainage in addition to medical treatment is highly recommended for better prognosis when NTM infection is associated with foreign body materials.

Increased public desire to attain and accentuate perceived physical beauty have motivated development of various cosmetic techniques that include lipolysis, acupuncture, and laser therapy. However, the possible risks and side effects of repetitive cosmetic procedures remain unclear. Infection, one of most critical side effects after cosmetic practices, can cause both physical and emotional distress. Bacterial infection goes through a natural course of acute exacerbation and recovery with antibiotics. However, in chronic infection, diagnosis and following treatments tend to be delayed, resulting in permanent sequelae. Therefore, in case of chronic infection, resistant to usual antibiotics regimen, it is helpful to consider the possibility of NTM infection for prompt diagnosis and treatment, and ultimately for a better quality of life in patients.

\section{Consent}

Written informed consent was obtained from the patient for publication of this case report and any accompanying images. A copy of the written consent is available for review by the Editor of this journal.

\begin{abstract}
Abbreviations
NTM: Nontuberculous mycobacterium; RGM: Rapidly growing mycobacterium; SSTI: Skin and Soft tissue infection; CRP: C-reactive protein; ESR: Erythrocyte sedimentation rate; CT: Computed tomography; AFB: Acid fast bacilli; TB/NTM PCR: Mycobacterium tuberculosis/non-tuberculous mycobactera polymerase chain reaction; MFC: Mycobacterium fortuitum complex.
\end{abstract}

\section{Competing interests}

The authors declare that they have no competing interests.

\section{Authors' contributions}

All authors of this case report made substantial contributions to conception and design. SY and SH drafted the manuscript. $\mathrm{KL}$ was involved in the microbiological investigation. SJ performed surgical procedures. All authors revised the manuscript critically, read, and approved the final version.

\section{Author details \\ ${ }^{1}$ Jeju National University School of Medicine, Jeju-si, Jeju, South Korea. ${ }^{2}$ Department of Microbiology and Immunology, Jeju National University School of Medicine, Jeju-si, Jeju, South Korea. ${ }^{3}$ Department of Plastic and Reconstructive Surgery, Uijeongbu St. Mary's Hospital, College of Medicine, The Catholic University of Korea, Seoul, South Korea. ${ }^{4}$ Department of Infectious Disease, Jeju National University School of Medicine, Jeju-si, Jeju, South Korea.}

Received: 23 July 2013 Accepted: 10 October 2013

Published: 16 October 2013

\section{References}

1. Jeong JH, Seo YH, Kim KH, Ahn JY, Park PH, Park YK: Mycobacterium wolinskyi infection confirmed by rpoB gene sequencing. J Clin Lab Anal 2012, 26(5):325-327.

2. Huang TS, Lee SS, Hsueh PR, Tsai HC, Chen YS, Wann SR, Leu HS, Ko WC, Yan JJ, Yuan SZ, et al: Antimicrobial resistance of rapidly growing mycobacteria in western Taiwan: SMART program 2002. J Formos Med Assoc 2008, 107(4):281-287.
3. Ariza-Heredia EJ, Dababneh AS, Wilhelm MP, Wengenack NL, Razonable RR, Wilson JW: Mycobacterium wolinskyi: a case series and review of the literature. Diagn Microbiol Infect Dis 2011, 71(4):421-427.

4. Lim JM, Kim JH, Yang HJ: Management of infections with rapidly growing mycobacteria after unexpected complications of skin and subcutaneous surgical procedures. Arch Plast Surg 2012, 39(1):18-24.

5. Brown-Elliott BA, Wallace RJ Jr: Clinical and taxonomic status of pathogenic nonpigmented or late-pigmenting rapidly growing mycobacteria. Clin Microbiol Rev 2002, 15(4):716-746.

6. Yang HJ, Yim HW, Lee MY, Ko KS, Yoon HJ: Mycobacterium conceptionense infection complicating face rejuvenation with fat grafting. J Med Microbiol 2011, 60(Pt 3):371-374.

7. Pai R, Parampalli U, Hettiarachchi G, Ahmed I: Mycobacterium fortuitum skin infection as a complication of anabolic steroids: a rare case report. Ann R Coll Surg Engl 2013, 95(1):e12-13.

8. Lee WJ, Kang SM, Sung H, Won CH, Chang SE, Lee MW, Kim MN, Choi JH, Moon KC: Non-tuberculous mycobacterial infections of the skin: a retrospective study of 29 cases. J Dermatol 2010, 37(11):965-972.

9. Dodiuk-Gad R, Dyachenko P, Ziv M, Shani-Adir A, Oren Y, Mendelovici S, Shafer J, Chazan B, Raz R, Keness Y, et al: Nontuberculous mycobacterial infections of the skin: A retrospective study of 25 cases. J Am Acad Dermatol 2007, 57(3):413-420.

10. Quinones C, Ramalle-Gomara E, Perucha M, Lezaun ME, Fernandez-Vilarino E, Garcia-Morras P, Simal G: An outbreak of Mycobacterium fortuitum cutaneous infection associated with mesotherapy. J Eur Acad Dermatol Venereol 2010, 24(5):604-606.

11. Karakala N, Steed LL, Ullian ME: Peritonitis from Mycobacterium wolinskyi in a chronic peritoneal dialysis patient. Int Urol Nephrol 2013, 45(1):289-291.

12. Pulcini C, Vandenbussche E, Podglajen I, Sougakoff W, Truffot-Pernot C, Buu-Hoi A, Varon E, Mainardi JL: Hip prosthesis infection due to Mycobacterium wolinskyi. J Clin Microbiol 2006, 44(9):3463-3464.

13. Chen YC, Jou R, Huang WL, Huang ST, Liu KC, Lay CJ, Chang SM, Tseng CE, Lai CL, Su YC: Bacteremia caused by Mycobacterium wolinskyi. Emerg Infect Dis 2008, 14(11):1818-1819.

14. Ohno T, Kishimoto W, Chihara D, Sakamoto T, Arimoto-Miyamoto K, Takeoka T, Tsuji M, Kida K, Ohkusu K, Ezaki T: First case report of sepsis caused by Mycobacterium wolinskyi in chronic myelogenous leukemia. Diagn Microbiol Infect Dis 2008, 62(4):433-436.

15. Narang R, Narang P, Jain AP, Mendiratta DK, Joshi R, Das R, Katoch VM: Mycobacterium avium bacteremia and dual infection with mycobacterium avium and Mycobacterium wolinskyi in the gut of an AIDS patient-first case report. Indian J Tuberc 2010, 57(3):148-151.

16. Yu JR, Heo ST, Lee KH, Kim J, Sung JK, Kim YR, Kim JW: Skin and soft tissue infection due to rapidly growing mycobacteria: case series and literature review. Infect Chemother 2013, 45(1):85-93.

doi:10.1186/1471-2334-13-479

Cite this article as: Yoo et al.: Facial skin and soft tissue infection caused by Mycobacterium wolinskyi associated with cosmetic procedures. BMC Infectious Diseases 2013 13:479.

\section{Submit your next manuscript to BioMed Central and take full advantage of:}

- Convenient online submission

- Thorough peer review

- No space constraints or color figure charges

- Immediate publication on acceptance

- Inclusion in PubMed, CAS, Scopus and Google Scholar

- Research which is freely available for redistribution 